\title{
A Quick, Economical and Easy Method of Skin Graft Fixation
}

\author{
Dhruv Chavan ${ }^{1}$ \\ G. Vishwanath ${ }^{1, \odot}$ \\ Bhushan Patil' \\ ${ }^{1}$ Department of Plastic and Reconstructive Surgery, Dr. D. Y. Patil \\ Medical College and Hospital, Pune, Maharashtra, India
}

Indian J Plast Surg 2021;54:379-380.

The immobilization of a skin graft is a key factor in its take of a skin graft.

Traditionally, a bolster dressing is used to secure and keep the graft immobilized on its bed. ${ }^{1}$ Its pressure obliterates dead space, and prevents hematoma and seroma formation.

This step usually falls toward the end of a long surgery, when anesthetic time may be at a premium and surgeon fatigue at its peak. Here, we describe a new method of graft immobilization which is effective, fast, and economical.

The method which uses a skin stapler and linen threads for bolster dressing is described here.

The skin graft is placed over the prepared recipient bed and fixed in the following manner. A free linen tie is placed over the margin of the wound, with one end long and the other end short but adequately long to hand tie a surgical knot, and the stapler is fired over the thread, fixing it to the graft and the bed ( - Fig. 1 ).

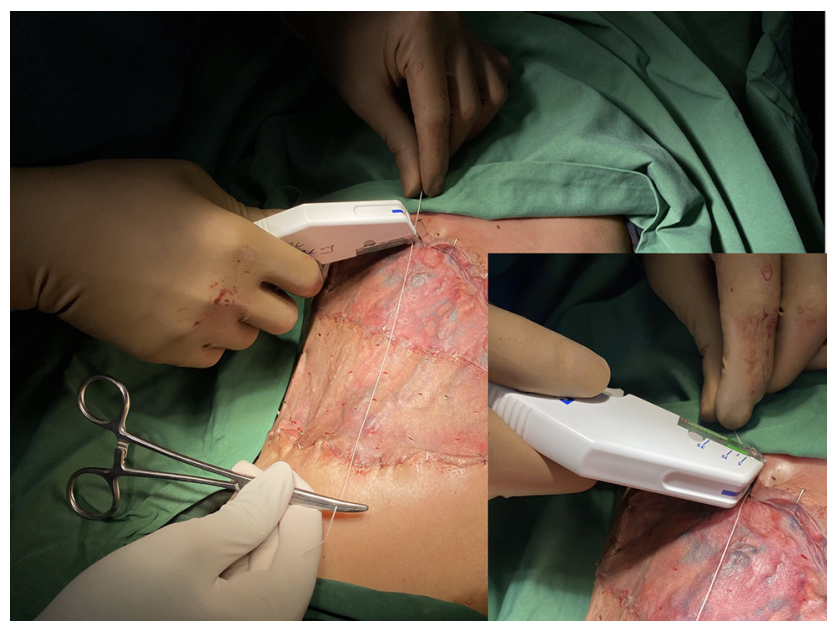

Fig. 1 Linen tie being placed across while the staple is being applied.
A surgical knot is then tied over the staple ( - Fig. 2).

The required number of such linen ties and staples are placed over the margin radially.

A bolster dressing is placed over the graft, and the linen ties are tied over it in the usual manner (-Fig. 3 ).

The traditional method of graft immobilization uses multiple sutures taken with a swaged needle and tied over a bolster dressing. This requires multiple foils of suture material, which is expensive and time-consuming.

A glove technique has also been described recently, ${ }^{2}$ in which a sterile glove is cut open and is fixed with staples outside one margin of the grafted wound, stretched over a cotton bolster, and then fixed outside the opposite margin.

A modified bolster dressing with the use of continuous suction is also described in literature. ${ }^{3}$

We have found the described "stapler and linen" technique to be quick, economical, and simple, as linen ties are

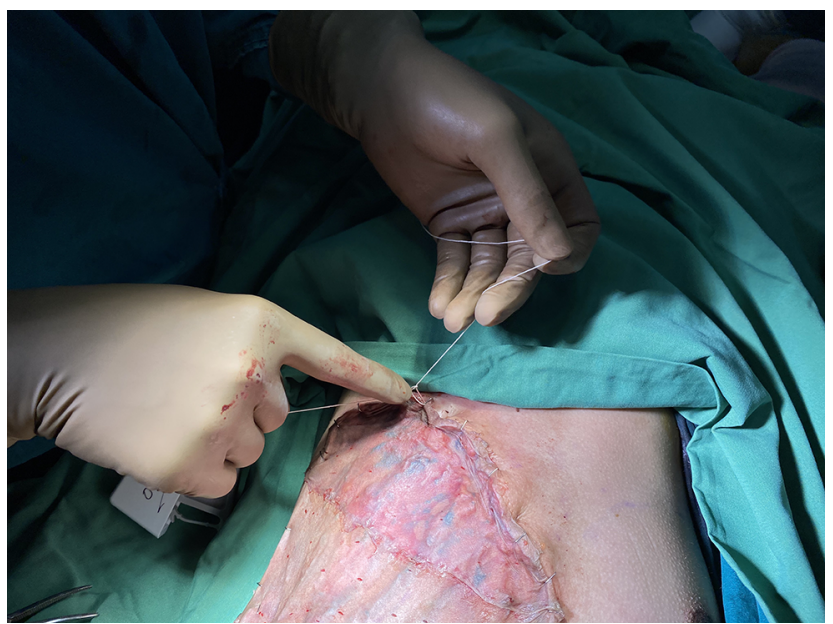

Fig. 2 Surgical knot tied with the linen thread over the staple. published online

September 16, 2021
DOI https://doi.org/

10.1055/s-0041-1734581 ISSN 0970-0358 (c) 2021. Association of Plastic Surgeons of India.

This is an open access article published by Thieme under the terms of the Creative Commons Attribution-NonDerivative-NonCommercial-License, permitting copying and reproduction so long as the original work is given appropriate credit. Contents may not be used for commercial purposes, or adapted, remixed, transformed or built upon. (https://creativecommons.org/licenses/by-nc-nd/4.0/).

Thieme Medical and Scientific Publishers Pvt. Ltd. A-12, 2nd Floor, Sector 2, Noida-201301 UP, India 


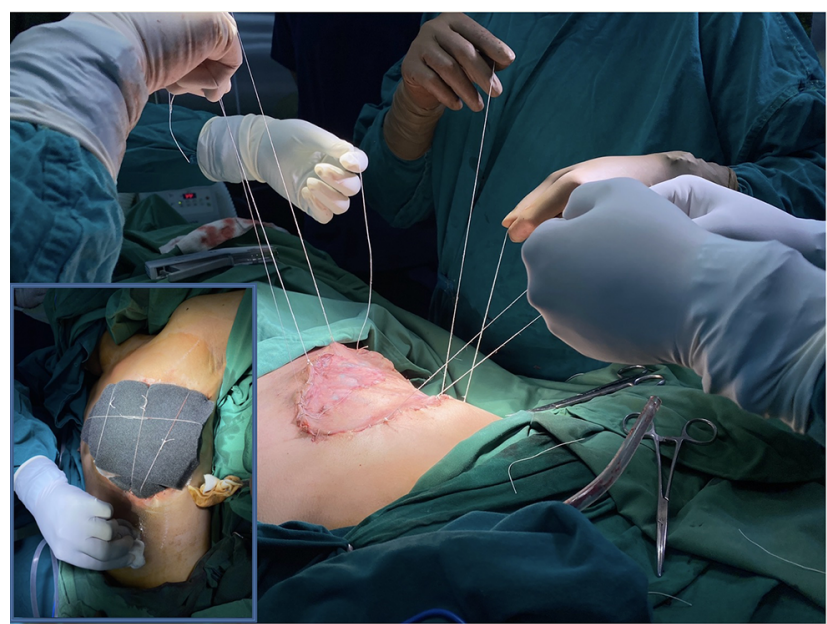

Fig. 3 Multiple linen ties taken; inset shows the same tied over bolster dressing. readily available in any OT, and the stapler is usually already in use in the procedure.

\section{Financial Support and Sponsorship}

Nil.

\section{Conflicts of Interest}

There are no conflicts of interest.

\section{References}

1 Hoffman HT, La Rouere M. A simple bolster technique for skin grafting. Laryngoscope 1989;99(5):558-559

2 Singh S, Bhatt YC, Doshi P, Vaghani SG. 'Glove technique' to secure skin grafts: A novel technique. Indian J Plast Surg 2016;49(1):127-128

3 Lee E, Park SI, Kim D, Jin H, Jeong HS. Modified bolster dressing with continuous suction improves skin graft survival for an oral cavity wound. J Otolaryngol Head Neck Surg 2018;47(1):68 